\title{
Comparative Study of Broiler Feeds Manufactured by Small Scale Manufacturers.
}

\section{By}

\section{Frank Shelton Windser Fernando}

Thesis submitted to the University of SriJayawardenapura for the award of the degree of Master of Science in

Food Science and Technology. 


\section{DECLARATION}

The work described in this thesis was carried out by me under the supervision of

Prof. Arthur Bamunuarachchi and Mrs.Indira Wickramasinghe and a report on this has not been submitted in whole or in part to any University or any other institution for another Degree / Diploma.

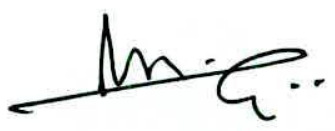

M. Frank Shelton Windser Fernando

Date: 24. 11. 2006. 
We certify that the above statement made by the candidate is true and that this thesis is suitable for submission to the University for the purpose of evaluation.

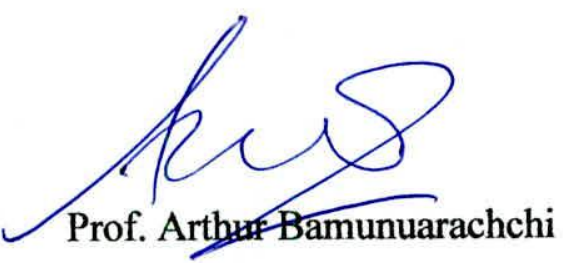

Head / Coordinator

Food Science and Technology Programme

Department of Food Science and Technology

University of SriJayewardenepura

Nugegoda, Sri Lanka.

Date:

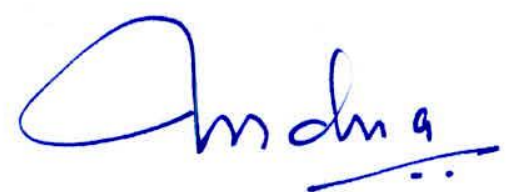

Mrs. Indira Wickramasinghe

Senior Lecturer / Supervisor

Department of Food Science and Technology

University of SriJayewardenepura

Nugegoda, Sri Lanka.

Date: 
AFFECTIONATELY DEDICATED

TO

MY LOVING WIFE AND DAUGHTERS 
Table of Contents ...................................................... V

List of Table ....................................................... VII

Acknowledgement …............................................. VIII

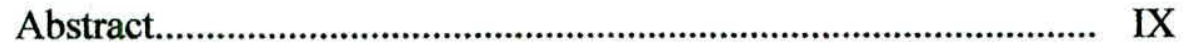

1.0. Introduction ................................................ 1

2.0. Literature Survey ............................................................... 4

2.1. Raw Materials for Compound Feeds. ...................... 4

2.1.1. Cereal Grain and Cereal Grain by- Products - Maize............ 6

2.1.2. Maize by-Products.............................................. 8

2.1.3. Rice and Rice by- Products................................................... 9

2.1.4. Cassava Meal and Sweet Potatoes. ....................... 10

2.2. Protein Sources and Their by-Products ....................... 12

2.2.1. Products of Vegetable Origin............................... 12

2.2.2. Ground Nut Meal ....................................... 14

2.2.3. Coconuts and by-Products..................................................... 14

2.2.4. The average composition of oil meals and by-products.......... 15

2,2.5. Products of Animal Origin................................... 15

2.3. Synthetic Amino Acids ...................................................... 18

2.4. Vitamin- Mineral Premixes. ................................ 18

2.5. Discovery of Aflatoxins ....................................... 19

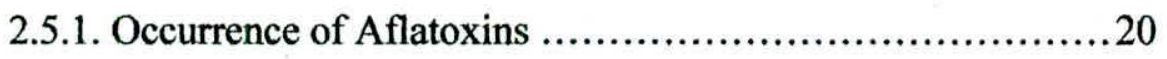

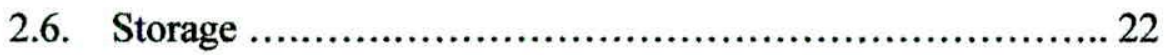


2.7. Standard Nutrient Level in Broiler Feed .................. 24

2.8. Feed Ration for Commercial Broiler Chicken............ 25

3.0. Experimental Methods............................. 26

3.1. Preparation of Samples............................ 26

3.1.1. Method ............................................... 26

3.2. Determination of Moisture ........................ 27

3.3. Determination of Crude Protein ..................... 28

3.4. Determination of Crude Fat ........................... 31

3.5. Determination of Crude Fibre ........................................ 33

3.6. Determination of Total Ash .......................... 35

4.0. Result and Discussion ............................ 37

4.1. Local Raw Materials................................... 37

4.2. Imported Raw Materials............................ 41

4.3. Final Products- Formulated Feed........................42

5.0. Conclusion................................................ 44

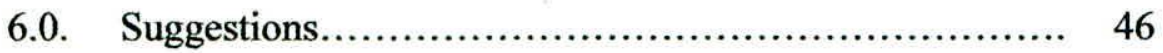

$7.0 \quad$ References..................................................................... 47

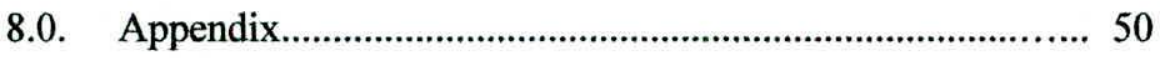




\section{List of Tables}

Table of Contents

Page No

2.1.5. The average composition of cereals and by-products............12

2.2.4. The average composition of oil meal and by-products.......... 15

2.2.6. The average composition of Animal Protein....................17

2.7.1. Optimum nutritive values of the common broiler feeds...........24

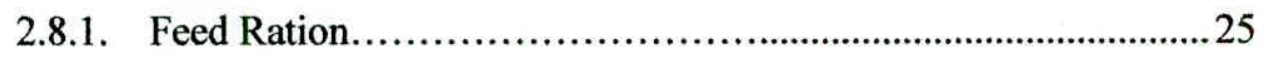

4.1.1.a. Proximate Analysis of Broken Rice........................... 37

4.1.2.a. Proximate Analysis of Rice Polish........................ 38

4.1.3.a. Proximate Analysis of Maize $\quad$............................. 39

4.1.4.a. Proximate Analysis of Sorghum........................... 39

4.1.5.a. Proximate Analysis of Coconut Poonac...................... 40

4.1.6.a. Proximate Analysis of Ground Nut Poonac.................. 40

4.1.7.a. Proximate Analysis of Soya Bean Meal..................... 41

4.2.1.a. Proximate Analysis of Fish Meal........................... 41

4.2.2.a. Proximate Analysis of Meat and Bone Meal................... 42

4.3.1.a. Proximate Analysis of Broiler Starter........................ .42

4.3.2.a. Proximate Analysis of Broiler Finisher.........................43 


\section{Acknowledgements}

First, I wish to take this opportunity to express my sincere thanks to Professor Arthur Bammunuarachchi, Head / Coordinator Food Science and Technology Program, and Mrs. Indira Wickramasinghe, Senior Lecturer / Supervisor, Department of Food Science and Technology, University of SriJayawardenepura for invaluable guidance and continuous encouragement extended to me throughout my study.

Further, I wish to acknowledge my gratitude to Dr. (Mrs.) U.L.P. Mangalika, Head of Animal Nutrition Division, Veterinary Research Institute, Gannoruwa, Peradeniya, for the intellectual suggestions, constant supervision given to me during this study, and Providing me the opportunity to undertake this project at the Veterinary Research Institute.

I also wish to thank Dr. K.K.D.S. Raneweera, Head, Department of Food Science and Technology, University of SriJayawardenepura, for his interest and guidance given throughout the project.

I am also thankful to Mrs.G.D.J.Kumari Gunarathne and Mrs.D.M. Manel Sirisena Veterinary Research Assistants, Animal Nutrition Division, Veterinary Research Institute, Gannoruwa, Peradeniya, for all the support given. 


\title{
COMPARATIVE STUDY OF BROILER FEEDS MANUFACTURED \\ BY SMALL SCALE MANUFACTURERS
}

\begin{abstract}
In Sri Lanka, poultry is the main monogastric animal reared for human food. The poultry sector has developed rapidly during the last twenty years period, the commercial chicken [Broiler] population accounted for highly increased of the total chicken population. The growth of the commercial production of broiler has achieved impressive results over the most recent years. This resulted in a significant contribution to meat consumption from domestic production.

The expansion of poultry industry, the feed industry has also been growing very quickly. Generally, feed is considered the major input for poultry production and may account for 65 to 85 percent of the total production cost. Since poultry, feed is composed of several raw materials, the cost and supply of raw material either produced locally or imported affects the feed industry. The raw material quality is very important to produce concentrated nutrient for the diet and Animal performance.

Feed ingredients are categorized on different groups as cereals, pulses, Animal products and their by-products. Various feeding rations are used in different broiler rearing areas in Kurunagela District, Kuliyapitiya area. It is important therefore to find ways and means to optimize the utilization of limited feed resources to reduce the cost of production of poultry meat.
\end{abstract}


Formulated feed quality depends on the type of raw materials and quality of raw materials. Complete knowledge about the nutritive value of raw materials is an important factor required for maximum utilization of any raw materials.

Proximate analysis was carried out for thirty-two broiler starter feed samples and twenty-eight broiler finisher feed samples and compared with the standard values to formulate the final best quality product.

This information will help in increasing of the use of locally available feed ingredients in feed formulation for monogastric animals, which will bring down cost of production, and increasing the quality of broiler meat. It will invariably help future growth of monogastric industry especially broiler chicken. Furthermore, scientists will be able to identify researchable areas to fill the gaps found present studies. Information will also help policy makers in important decision-making. 


\section{Chapter I}

\section{Introduction}

Birds (poultry) eat food, which gives them the energy necessary for the function of their bodies and the materials indispensable for their products meat and eggs. To keep them in good health and allow them to attain maximum production, their needs must be supplied. It has been observed that results were optimal, both as regards hygiene and zoo technical performance, when feeding was balanced, that is when it satisfies all their needs without even one element of the diet being excessive in relation to the others.

Scientifically research has made it possible to determine the feeding requirements of specialized strains. (Meat producing)

At the practical level, development of balanced diets begins with calculation of a ration, which approaches the scientifically determined requirements by combining characteristics of the raw materials, as defined by many chemical analyses.

Calculation of rations leads to a feeding cost reduction by reducing poultry losses, by ensuring the best possible zootechnical performances and by economizing in feeds.

The raw materials used in poultry feeding are agricultural products (cereals), agroindustrial by-products (oil cakes, miller's and rice chandler's wastes, molasses and brewer's grains), 
Animal by-products (blood meal, bone meal, meat meal, fish meal, feather meal) and chemical industries products (minerals, trace elements, synthetic vitamins and amino acids, additives)

The purpose of feeding broiler is to convert feedstuffs into broiler meat, rations are a major concern. Feed costs vary with the cost of ingredients but normally feed costs for broiler are $65-85 \%$ of the cost of production of the live broiler. The feed they consume is a complete ration. Broiler feeds are generally fed as crumbles for the starting feed and pellets for the remainder of the growing period. [Carmen and George, 1987]

Various types of feeding program are currently being considered by broiler producers and feed manufacturers, and these may be thought of as specialty feeds.

These programs may involve low nutrient dense diets as a means of simply reducing feed cost, or diets of higher protein / amino acid content used in an attempt to reduce carcass fat content.

Low nutrient density program by offering low protein, low energy diets, reduces feed cost and so make feeds more attractive to customers. However, the birds will Necessarily consume more of these diets and that birds may take longer to reach market weight.

With low energy diets therefore, we can expect slightly reduced growth rate, because normal energy intake is rarely achieved, and this fact is the basis for program aimed at reducing early growth rate. Carcass weight and meat yield are often reduced, and which is associated with increased deposition of carcass fat, especially in the abdominal region. [Leeson, 1997] 
Diets for improved meat yield program can be manipulated in order to advantageously influence the composition of the broiler and roaster carcass. This effect of reducing the energy level is due to reduced carcass fat content rather than any measurable increase in carcass protein content.

Poultry meat [Broiler] is ideally suited to meet the increased demands for animal product with improved efficiency of production. The success of the broiler chicken in Sri Lanka is now being mirrored around the world due to four major factors.

Ease of establishing integrated operations

Economically competitive price of poultry vs red meat

Adaptability for further processing

Meat composition in relation to Human Health 


\section{Chapter II}

\subsection{Literature Survey}

Feed materials are broadly classified as roughage or forage and grains or concentrates. Roughages are high in cellulose or related compounds and are generally less digestible, particularly in the simple stomached animal. The grains are in general characterized by low cellulose content and high digestibility and energy values. [R. Ralph, 1987]

Feed materials include;

\section{Forage crops}

Seed, root grain and by-products

The utilization of various products from either plants or animal origin depends upon the digestibility and nutrient value of these materials.

\subsection{Raw Materials for compound Feeds:}

Raw materials for feed or feed ingredient are the building stones of a compound feed. Before attempting to formulate a balanced, compound feed for broiler, we need to pay attention to the ingredients.

Identified and recognized the different ingredients

Used our eyes, nose, and our touch- but do not taste 
* Know the origin(Animal/Plant ) what product are they or from what process are they (by) products

Look for their strong and week properties, the effect they have on the feed, the animal and it's performance

To what extend can we use them in different feeds.

The amount of nutrients in cereal grains varies considerably from species to species. Soil, climate and added fertilizer also affect their composition. Processing can reduce the nutritive content of the grains.

Cereals play an essential role in the animal food supply. The efficiency of the use of the would food resources will improve a lot if animals are fed foodstuff which are unsuitable for human consumption (poor quality or waste product from food processing). Animal can convert otherwise useless raw materials into very valuable animal product, and thus contribute to the food supply.

The present project was conducted in Kurunagela district, Kuliyapitiya divisional secretary area, selected twenty-two small-scale broiler feed manufactures. In this area, mostly available raw materials are, Maize, Maize bran, Sorghum, Paddy, Broken rice, Rice bran, Rice polish, Coconut poonac, Cassava and Sweet potato, Soybean and soybean by-products.

Feed manufactures are using in the above region, in these ingredients for their feed formulation. 